\title{
Research Seminar Reports
}

\author{
Researching the media: student research at the University of North London \\ DAVID NICHOLAS \\ School of Information and Communication Studies \\ University of North London
}

With ever-increasing demands on university lecturers' time (largely to do more teaching) the University of North London is looking for greater collaboration with its students to maintain its research profile. Dissertation students on both the BSc and MA levels are encouraged to pursue topics in areas where the University believes it is strong and should maintain its presence. Students are also enjoined to publish their findings more widely in the professional journal literature, perhaps in collaboration with their supervisors.

The School has always had a strong presence in the media field and we were the first library school to obtain funding from the BLRDD to research the press and broadcasting field (Information seeking in an information society, 1986-1987). Our proximity to - and close links with - the principal media organizations in the field helps. What follows is a selection of our student research undertaken during the period 1992-1993. This particular selection illustrates the extent of our interests, for these studies take in the television, radio and book publishing fields. All three of these studies featured extensive field research and provide new and original material.

The papers by Margaret Katny and Catherine Harada are based on their successful MA (Information Studies) Dissertations while Pan Pandit's paper is based on her equally successful final year BSc dissertation. All three were given at a LIRG South-east meeting on 5 October 1993.

\section{Newspaper cuttings collection and online information systems at the BBC World Service Information Research Unit}

\author{
MARGARET KATNY \\ School of Information and Communication Studies \\ University of North London
}

Based on research conducted between July and December 1992, this paper aims to investigate the frequency of online searching and volume of cuttings usage in order to answer enquiries from journalists. It presents the level of satisfaction with the two information sources, points out their advantages and drawbacks and examines their value from the point of view of journalists and information assistants.

It attempts to explore how online systems compare with newspaper cuttings in terms of value of information, speed of access, retrieval and use, ease and convenience of use, currency, retrospectiveness and completeness of information content, source coverage, cost effectiveness, physical properties, and graphic presentation. The paper examines users' preferences and their perception of future roles of online systems and press cuttings. 
The report seeks to test the hypothesis that press cuttings are the most favoured and popular information source - much desired, most familiar, very fast and effective.

The BBC World Service Information Research Unit provides an information and research service to World Service programme makers. Its cuttings collection comprises over 20 million cuttings, some of which date back to the 1930s. All members of staff are daily involved in various stages of marking, cutting, sticking, sorting and filing cuttings. The Unit has access to three online information system: FT Profile, Nexis and Blaise-Line. It also has access to EDiT - Editing, Distribution and Translation system, which is a powerful database for dissemination of internal data.

The report is to a large extent the result of two surveys: one aimed at journalists using press cuttings to research their programmes and one aimed at information assistants who use press cuttings files to provide information. Fifty questionnaires were distributed to journalists and 26 were completed and returned, which constituted a reasonable response rate of $52 \%$. Questionnaires were also handed out to all 23 information staff and all but one were returned, giving an excellent response rate of $95 \%$. Statistical data, such as volume of usage of information sources, was examined on the basis of Information Unit's enquiry logs which contain the details of all the enquiries answered by the Unit.

The Information Research Unit handles a great number of enquiries and these have grown over the past decade. In 1992 the Unit handled nearly 42,000 (41,939) queries or an average of nearly 3,500 a month $(3,495)$. A majority of queries were satisfied in a very short period of time - $83 \%$ of all enquiries recorded during the study period were answered in less than 10 minutes.

The analysis of the enquiry logs revealed that out of the total number of enquiries recorded during the July-December period, $64 \%$ of queries were answered fully or partly by reference to cuttings $(13,498$ out of the total of 21,143$)$. The remaining $36 \%$ were satisfied by means of online systems, books, news bulletins, and other internal BBC or external sources.

Enquiries involving the usage of press cuttings can be divided into two groups: enquiries which were answered using cuttings as the sole source of information and enquiries which required the usage of cuttings to be supplemented by other sources of information. This distinction appears to be slight but in fact it is very important.

The analysis of enquiries involving cuttings showed that the majority of them - 71\% - used cuttings as the one and only information source. If we relate the number of enquiries answered by cuttings as the sole source of information to the total number of queries recorded, it becomes evident that an average of $45 \%$ of the total of all queries handled by the Unit utilized cuttings as the sole source of information.

What this means in practice is that once cuttings are chosen as a method of answering an enquiry, other sources need to be consulted relatively rarely. When they are consulted, they are usually books, or less often, BBC internal news bulletins. Out of all enquiries involving cuttings, an average of $29 \%$ queries combined cuttings with other sources. Interestingly enough, cuttings were rarely used in conjunction with online searching - only $2 \%$ of queries involving cuttings and other sources used cuttings and online databases.

The majority of enquiries involving cuttings are of very short duration - $80 \%$ of them took less than 10 minutes $(10,754$ out of 13,498$)$. It appears that looking for information in cuttings files is a fast process.

Enquiries answered by means of online searching are much less in evidence. During the study period the Unit handled only 551 enquiries which were answered by online searching - which accounts for $2.6 \%$ of the total number of enquiries handled in that period. This means that the average number of online usages was three searches per day. Furthermore, there were 29 days (usually Saturdays and Sundays) when not a single online search was conducted.

As in the case of cuttings queries, online queries can be divided into ones which are answered only and exclusively by the results of an online search and queries involving other sources of information. The research showed that only an average of $11 \%$ of all queries involving online sources used online databases as the sole source of information (60 out of 551). The remaining $89 \%$ of queries involving 
online used online searching combined with other sources of information (491 out of 551). The obvious conclusion is that online searching is far more likely to be supplemented by other sources rather than be used by itself. It is also worth mentioning that the source most often combined with online searching is press cuttings - $46 \%$ of all enquiries involving online searching required the usage of cuttings as well (255 out of 551).

Duration of enquiries involving online searching was, on the whole, rather longer than those involving press cuttings. Online searching queries most often took between 11 and 30 minutes to answer - nearly $56 \%(55.9 \%)$ of all online queries were of that duration (308 out of 551) with a somewhat smaller number of queries $-42 \%(41.7 \% ; 230$ out of 551$)$ - lasting 10 minutes or less.

Patterns of usage of press cuttings and online systems in the Unit appear to be entirely different. Cuttings emerge as a major, heavily used method of accessing information whereas applications of online systems appear to be very limited.

The second part of the research aimed to investigate respondents' attitudes to the two sources of information.

Respondents were asked how satisfactory they found press cuttings in supplying them with information they required. It turned out that the degree of user satisfaction with press cuttings was very high. Sixtynine per cent of journalists surveyed and $82 \%$ of information staff said that cuttings satisfy their needs in $75 \%$ of cases. A further $23 \%$ of journalists and $18 \%$ of information staff declared that cuttings satisfy their needs in 100\% of instances. It is significant that not a single information assistant assessed cuttings as having less than a $75 \%$ success rate. Only $8 \%$ of journalists claimed that cuttings satisfy their needs in less than $75 \%$ of cases.

The low level of online use was reflected in the limited familiarity of users with online information. Sixty-nine per cent of programme makers taking part in the survey admitted to having no knowledge or experience of using online systems. The majority of information assistants (77\%) identified their familiarity with online systems as average or limited, though some did have extensive or very extensive knowledge of online systems. Half of them were acquainted with one online system (FT Profile).

A very interesting part of the survey was the examination of what respondents considered to be advantages and disadvantages of press cuttings and online systems.

Both journalists and information assistants seemed to have a very clear idea of what they like about press cuttings. They considered the content of cuttings files highly valuable, offering satisfactory coverage of sources, including background material and retrospective as well as up-to-date information. Journalists appreciated original graphic presentation of stories (such as typefaces, headline sizes and pictures), while information staff regarded cuttings most highly for the speed, ease and flexibility with which they could be accessed. Both groups of users appeared to think that cuttings were user-friendly - they described them as easy and fast to use, convenient, browsable and full of flavour.

Disadvantages, on the other hand, appeared to be closely connected to the format and physical properties of cuttings: they were likely to be in a poor condition, they were thought to be bulky, difficult to store, messy, liable to loss, theft, wear and tear, misfiling and lack of order. The two major disadvantages of cuttings according to information staff turned out to be related to tasks undertaken in order to maintain the collection: dependence on markers' judgement and labour-intensive daily routine of cutting, sticking and filing. Only two drawbacks referring to file contents were listed: cuttings were considered to be difficult to search for specific data and not entirely reliable or accurate.

To complete the picture of press cuttings, journalists and information assistants were asked to assess cuttings with respect to such features as ease of use, currency and retrospectiveness of information, completeness and source coverage. This part of the survey revealed that cuttings were valued very highly indeed. Very few or virtually no respondents believed cuttings were "poor" or "very poor" with respect to any of the features. Currency of information contained in press cuttings received excellent rating from journalists, with completeness of information receiving the least favourable rating, being considered only average. In the view of information assistants, ease of use and currency of information were held in the highest esteem, with ratings for retrospectiveness not very far behind. Information 
assistants judged completeness of information and source coverage to be good though perhaps edging towards being average rather than excellent.

Journalists and information assistants were asked to list what they thought were advantages and drawbacks of online sýstems. Journalists' assessment of online turned out to be rather shallow - they provided less complete and less comprehensive answers than those offered to similar questions concerning press cuttings. This had probably a lot to do with their limited familiarity with online systems. Twelve respondents, representing $46 \%$ of all surveyed, did not list any features of online which diminished the statistical significance of data. However, this fact in itself can be considered meaningful.

Information assistants and to a certain extent journalists, appeared to view online systems from the perspective of cuttings collections. Significantly enough, they hardly ever tended to refer to online systems when they were assessing cuttings files.

Journalists appeared to look at online from a very practical point of view of its usefulness; in their view the greatest advantage of online systems was the fact that clear, easy to read and uniform printouts could be readily obtained. Information assistants thought the advantage to be their function as a backup system to compensate for drawbacks of cuttings. Their source coverage, though judged to be broad, was thought to be useful as long as it included sources not cut or taken by the Unit. Having said that, respondents did point out online's suitability for finding highly specific material. Online searching was judged to be fast.

As far as drawbacks go, information assistants viewed cost of online systems as their major disadvantage. Journalists, on the other hand, disliked the fact that online lacked additional information provided by graphic presentation - which was one of the main advantages of cuttings. Information staff criticized online systems for offering very limited browsing possibilities and pointed out that databases lacked older material as well as very current material.

It has to be mentioned that the respondents' listing of online drawbacks showed some inconsistencies. For example, they judged online to be slow, although fast access and retrieval was also listed as online's advantage; they claimed online databases forced them to be specific, although specificity was a rather prominent advantage of online.

An important aspect of online systems use is their cost-effectiveness and I think it needs to be mentioned separately. Information assistants were requested to voice their opinions upon cost-effectiveness of online systems. Their responses suggested they felt online systems could, or had the potential to provide value for money under certain circumstances. Fifty-five per cent of staff agreed that online systems provide value for money "to some extent" (12 respondents). It appears that information staff acknowledged the benefits of online systems despite the fact that high cost was listed by $82 \%$ of respondents as the major drawback of online systems.

To complete the investigation of information staff attitudes towards online systems, it seemed necessary to find out the circumstances in which the staff tended to use online databases rather than other information sources. Information assistants said they used online:

- when information could not be found in cuttings files (21 respondents, 95\%) - with the exception of one respondent, all members of staff agreed that the major reason for conducting online searching was unavailability of information in cuttings files;

- $\quad$ when specific material was required (12 respondents, 55\%);

- when information was expected to be found in sources not cut or taken (eight respondents, 36\%);

- when all other options had failed (four respondents, 18\%);

- when it was quicker and easier (three respondents, $14 \%$ );

- when online could be used for checking information already available (two respondents, 9\%). 
Circumstances in which online systems are used point to their secondary importance in relation to cuttings. It was made clear that information assistants considered online systems to be a supplementary source, a convenient backup system able to compensate for some of press cuttings' weaknesses.

Having said that, it is interesting to note that the majority of staff (15 respondents, 68\%) believed that acquiring information from online databases increased their professional status "to a certain extent".

Finally, having expressed their opinions about both press cuttings and online systems, journalists and information staff were asked about their preferences. The majority of respondents, both journalists and information assistants, declared that they preferred to use cuttings rather than online databases. Sixtyone per cent of journalists surveyed (16 respondents) preferred to use cuttings and $35 \%$ or nine respondents stated they had no preference. Seventeen information assistants voiced their strong preference for cuttings and the remaining five people declared no preference for either source of information. Not a single respondent preferred to use online databases.

Furthermore, the majority of information staff were negative in their responses about online systems' potential to replace cuttings though some of them admitted that online systems might have the capability to replace cuttings (three respondents). All respondents, both journalists and information assistants nearly unanimously acknowledged that they did not consider it desirable for the World Service Unit to stop its cuttings collection and to rely only on online systems. Significantly, those staff members who claimed that online systems might just have the potential to replace press cuttings ultimately declared no wish for the replacement to take place.

It appears that online systems, though not devoid of merits, have no potential to compete with press cuttings. Cuttings are a distinctive feature of the BBC World Service Information Unit and they seem to be there to stay, at least for the foreseeable future. Information provision in the Unit is to a large extent dominated by and dependent upon press cuttings collections and both journalists and information staff find them extremely satisfactory. It would appear then, that the hypothesis of this report is confirmed: press cuttings are definitely a very much used source of information - desired, familiar, effective, valuable and tailor-made. For the time being press cuttings are a genuinely indispensable source of information.

\title{
Sexism in children's picture books: an update
}

\author{
CATHERINE HARADA
}

School of Information and Communication Studies

University of North London

Sexism in children's picture books has been the subject of much research and discussion during the last two decades. Sociologists and psychologists as well as specialists in children's literature deplored the fact that females were rarely the leading characters in picture books and that both sexes were portrayed in highly stereotyped ways. As sexism in picture books is now rarely discussed except in the occasional column announcing the failure of non-sexism, a quantitative survey of sexism in contemporary children's picture books was due.

The studies from the 1970s analyzed primarily prize winning and best-selling books. This study is not limited to these books but surveys a larger sample of the books available to children. Prize winners were not excluded, but as they may be assumed to be superior to the average book, a larger survey provides a more representative sample. A random $10 \%$ of the picture books, available at six inner London libraries, which were published between 1986 and 1992, a total of 407 books, were examined for this project.

The survey was designed to examine the factors singled out as sexist by earlier researchers as they occur in contemporary children's picture books. The numbers of male and female main characters, the numbers of males and females in illustrations, and the occurrence of 14 stereotypical behaviours were recorded. The traditional stereotype male role elements tabulated were leading, rescuing, misbehaving, 
problem solving, striving to achieve, adventurousness, and dealing with technology. Following, nurturing, showing emotion, doing housework, being rescued, being a victim of violence, and being concerned about appearance were the stereotype female role behaviours recorded. The incidence of each behaviour was noted for both male and female characters.

The results showed that females are far more frequently found as main characters and in illustrations in children's picture books published between 1987-1992 than in pre-1972 picture books. The typical character of both sexes was considerably softened from the sex role stereotype model. Although the outline of the traditional stereotype character can still be perceived, the treatment of both male and female characters has moved toward the middle ground, with both sexes involved in activities formerly reserved for the opposite sex.

Males were the main character in $34 \%$ of the books studied, females in $23 \%$, both males and females in $34 \%$, and characters of indeterminate gender were the stars of $9 \%$ of the total. Over the years stúdied, the proportion of books with males alone or paired with a female main character rose at the expense of books with female main characters, while the proportion of unsexed main characters remained fairly steady.

If the total number of main characters is examined, there were 1.23 males for every female. When animals are considered separately, the figure is 1.9 to 1 . Although unequal, this ratio represents a tremendous change from the 95 to 1 reported by Weitzman in 1972. Among the human characters, there were actually more female main characters $(50.3 \%)$ than male, and the most common main character in the picture books examined was a female child.

The high number of female main characters but the larger proportion of books with male main characters is due to the fact that females are often part of a pair or group of main characters. Weitzman found that female characters were seldom seen with friends; this is no longer the case. The concern raised by these figures is that females are not considered strong enough characters to carry the reader's interest alone. The prevalence of paired male/female main characters looks like a response to the old belief that while girls will read a book about a boy, boys will not read a book about a girl. By pairing male and female characters, authors keep all potential readers while avoiding the charge of sexism.

Although male/female roles were not drawn to strict stereotype as was found by earlier researchers, slightly more than $60 \%$ of the overall recorded behaviours were associated with characters of the traditional sex. Some behaviours were quite different from the sex role stereotype: $67 \%$ of followers were male, and $48 \%$ of rescuers were female. Appearance, housework, and nurturing were still primarily but not exclusively female concerns, however, but $50 \%$ of the victims of violence were male. Females were involved in about $40 \%$ of the problem solving and achievement related behaviour and slightly more of the naughtiness. Human variability is now reflected in the world of picture books.

Non-sexist books of the past are often self-consciously correct to the point of anti-stereotype stereotypes. Women characters are super competent; they work as window washers, members of the fire brigade or drive earth moving equipment. The few male characters who appear in such books operate in the traditional female sphere, are incompetent, or both. In the contemporary books surveyed, such characters are rare. If characters behave untraditionally, it is treated as a natural part of the story. Fictional fathers can appear at the school gate without exciting comment; this only mirrors modern reality.

The only instance of untraditional behaviour being treated as abnormal occurred in a book with Asian characters. Books published in Asia and books with Asian characters reflect the more traditional sex roles of Asian men and women. Girls still stay at home and help Mummy in such books, while boys go out and have adventures. Perhaps the unrealistically untraditional charactizations in the first book represent a phase on the way to a more balanced, less stereotypical presentation of male and female characters.

Picture book illustrations parallel the texts in representation of the sexes. Of 21,569 figures of discernable sex in the 407 picture books, 55\% were male. This is as close to equality as can be reasonably be expected, far more equal than was found twenty years ago. Females were shown in $50.5 \%$ of the 5,262 indoor pictures and $43 \%$ of the 5,268 outdoor pictures. This is a very pale reflection indeed 
of the female character of the past who rarely made it past the front porch. The same shadow of past stereotypes may be discerned in the figures for large and small characters. Although children of the same age were almost uniformly drawn the same size, when children were shown with older or younger children, the older was slightly more often male and the younger female.

Each book was assigned a traditionalism rating based upon the conformity of the characters to traditional sex role stereotype behaviour. Although the ten most frequently borrowed books were mostly untraditional books, there was no clear trend when the entire sample was considered. This at least contradicts those who have claimed that non-sexist books are uniformly boring and unappealing to children.

There is an equal lack of support for the theory that men write sexist picture books. Books with a predominately traditional representation of the sexes were the largest proportion of books by both men and women authors - 55 and $56 \%$ respectively.

Both publishing and library establishments have disclaimed sexist books. Indignant activists have made most authors and illustrators well aware of the problems of sex role stereotypes. Perhaps even more effective in reducing sexism in children's picture books are the societal changes which have gradually entered the collective consciousness over the past 20 years. I found the world of picture books reflecting the roles of men and women without unconsidered stereotypes and in fairly equal numbers. This healthy state of affairs was a long time in arriving, but the characters in pictures represent a rich variety of models for children.

\section{Selected bibliography}

Czaplinski, Suzanne. Sexism in award winning picture books in: Sexism in children's books: facts, figures and guidelines. Children's Rights Workshop. Writers and readers publishing cooperative, 1976, pp31-38.

Fisher, Elizabeth. The second sex, junior division. New York Times Book Review, 21 May 1970, pp6 and 44.

Nilsen, Alleen Pace. Women in children's books. Report of a working party convened by the Education Publishers Council. London: The Publishers Association, 1981.

Stewig, John and Higgs, Margaret. Girls grow up to be mommies: a study of sexism in children's literature. Library Journal, 98(2), 1973.

Stones, Rosemary. 'Pour out the cocoa, Janet': sexism in children's books. York: Longman, 1983.

Weitzman, et al. Sex role socialization in picture books for pre-school children. American Journal of Sociology, 77(6), May 1972, pp1125-1150.

\section{What lies ahead .....? Looking into the future of independent broadcasting libraries in England and Wales}

\section{PANKAJPANDIT}

School of Information and Communication Studies

University of North London

Over the past couple of years the broadcasting industry has been in a state of flux. Several reasons have contributed towards this discontentment - the recessions and consequent decline in advertising revenue, and competition from satellite and cable stations. However, the main contention has been the enactment of the Broadcasting Act 1990. The philosophy behind the Act was to increase competition and to give way to a free market broadcasting environment. Many ITV companies made substantial bids for the franchises in order to retain their licenses - Yorkshire bid $£ 37.7$ million whilst Carlton bid $£ 43.2$ million for the London weekday license held by Thames. However, in order to compete adequately within such 
a commercial market and at the same time provide good quality programming, large amounts of capital are required, and as a result many ITV companies are likely to be short of revenue. The future obligation to buy up to $25 \%$ of programming from independent producers has spurred companies to slim down their own in-house production facilities, becoming "publisher/broadcasters" rather than "producer/ broadcasters", thus reducing staff and services. Some companies have decided to merge in order to overcome this financial dilemma, for example a cost-saving merger was the takeover of Tyne Tees by Yorkshire Television in June 1992.

Why independent broadcasting libraries? With the recent award of the 1991 franchises, many ITV companies have had to make economies and it has been the libraries that have had to endure proportionally more of the burden than any other service. The research set out to examine and investigate 15 ITV libraries in England and Wales - 75\% responded. The main objectives of the research were to assess the significance and importance of the 'media library' in independent broadcasting companies, to investigate what became of the libraries in companies which lost their franchises, and to explore the extent of library or research provision provided by the new franchise companies.

In the past libraries have been perceived as optional extras rather than a necessity. Broadcasting libraries serve and support a variety of different production and technical departments, gathering information from a varied selection of material, ranging from film/video-tapes, stills, press-cuttings, programme excerpts to books for reference and general use.

The main casualty of the 1991 franchise awards was Thames Television, established in 1968. The company had three separate library services holding material dating back to 1955 . There was some speculation that Thames could become profitable as an independent production and distribution company rather than as a broadcaster, selling some of its archive material such as the "The Bill" and "Minder". Once Thames lost the franchise and programme making ceased, the company made radical staff cuts. Libraries were targeted and shut down. In 1989 there were 16 members of staff in the libraries but in 1992 only five remained and at present there is only one librarian. Much of the paper and programme material that was held in the libraries was either sold, taken over by the BFI, donated to other ITV companies or simply dumped. This has had serious implications on the preservation of valuable television history.

With the trend of ITV companies moving towards becoming publisher/broadcasters rather than producer/broadcasters, the lack of in-house programming does mean that libraries do face a very uncertain future. Many libraries are having to justify their existence. As profitability becomes a more immediate concern for many broadcasting companies in the 1990s, realization of the value of library material is only just beginning to dawn (preserving programme material for the company's own re-use or for sale). More and more libraries are moving towards becoming fee-based information and profit making centres. Librarians too are having to reassess their roles, since many feel that their traditional role of information provider is being eroded as the industry enters a new era where the pace of competition grows daily. Many librarians are adopting a proactive stance (selling and marketing their services) and increasingly taking up the role of information brokers or consultants.

The new franchise holders, namely Carlton, Meridian, Westcountry and GMTV, being publisher/ broadcasters do not require large research and information library facilities. However they do maintain a limited library service, holding some reference books but mainly retaining film/video-tape/stills of inhouse news footage which can be marketed.

As 1993 draws to a close, the broadcasting industry faces further upheaval as the liberalisation of the franchise ownership comes into effect.

Companies will be able to hold two licences, resulting in a wave of takeovers and mergers - this could mean a contraction in the number of commercial television operators from 14 to eight. What will become of the libraries now? 